\title{
The Value of Tropical Forest to Local Communities: Complications, Caveats, and Cautions
}

\author{
Douglas Sheil and Sven Wunder ${ }^{1}$
}

\begin{abstract}
The methods used to value tropical forests have the potential to influence how policy makers and others perceive forest lands. A small number of valuation studies achieve real impact. These are generally succinct accounts supporting a specific perception. However, such reports risk being used to justify inappropriate actions. The end users of such results are rarely those who produced them, and misunderstanding of key details is a concern. One defense is to ensure that shortcomings and common pitfalls are better appreciated by the ultimate users. In this article, we aim to reduce such risks by discussing how valuation studies should be assessed and challenged by users.

We consider two concise, high-profile valuation papers here, by Peters and colleagues and by Godoy and colleagues. We illustrate a series of questions that should be asked, not only about the two papers, but also about any landscape valuation study. We highlight the many challenges faced in valuing tropical forest lands and in presenting and using the results sensibly, and we offer some suggestions for improvement. Attention to complexities and clarity about uncertainties are required. Forest valuation must be pursued and promoted with caution.
\end{abstract}

\section{INTRODUCTION}

Improved methods for the valuation of tropical forests and forested landscapes are often highlighted as critical for better land use policy in the humid tropics. To date, various texts discuss "how it should be done," but few applications have attracted wide attention. Here, we consider two high-profile valuation studies that specifically address local community perceptions. The first of these is old enough for us to have the full benefit of hindsight. The second is more recent. Our main argument is that, although these studies are attractive and persuasive, they deflect adequate attention to the many pitfalls that underlie all such studies. Economic information out of context, however well intentioned, can too easily lead to inappropriate conclusions. These may, in turn, lead to misguided actions. On the other hand, researchers are constrained in terms of time and budgets, limiting just how many details they can effectively explore. In addition, for valuation research to have an impact on policy and on decision makers, conclusions require brevity and cannot be complex.

In recent years, there has been an emerging awareness that policies develop in a relatively informal way. Faced with diverse demands with large numbers of unknowns and uncertainties, policy makers place considerable faith in what might be termed the "conventional wisdoms" of a given field of enquiry. Policy makers are often receptive to simple slogans with apparent scientific credentials (Cohen et al. 1972), and may actively seek to exploit them (Garrett and Islam 1988, Keeley and Scoones 1999). Deceptive "narratives" are increasingly blamed for many issues of environmental mismanagement, from the mishandling of Ethiopian droughts (Hoben 1995) to the eviction of Guinea's farmers from the forests that they themselves had perhaps created (Fairhead and Leach 1995). In this account, we do not wish to explore policy development. However, we do assume two points: first, that research can have a deep, but indirect, influence on policy (Keeley and Scoones 1999); and second, that simple generalizations stand the best chance of gaining that influence (Scott 1998). The trouble is, as we will contend, that simplification is often misleading. Faced with the classic dilemma between a complex reality and a streamlined framework for decision making, we develop a guiding "checklist" for those who plan studies and for those who assess them.

Our paper is structured as follows. We examine a 1989 article that has become a classic in the literature on 
nontimber forest products (NTFPs; Peters et al. 1989), and describe problems related to it. We briefly assess this study's impact, focusing on its misleading aspects. We also examine a more recent study, Godoy et al. (2000), and compare it with Peters et al. (1989). We then discuss a range of methodological questions that could be asked about any study, regarding objectives, uncertainties, context and extrapolation, and interpretation. Finally, we summarize our main conclusions.

\section{PETERS ET AL. (1989)}

Thirteen years ago, Charles Peters, Alwyn Gentry, and Robert Mendelsohn published a two-page article in Nature (Peters et al. 1989) that changed the world's perception of NTFPs. They combined botanical survey data from a 1-ha forest plot in Mishana $(30 \mathrm{~km}$ from Iquitos, Peru) with monthly retail prices for fruits and latex in the Iquitos market. The gross annual per hectare value of these NTFPs was almost US\$700; deducting labor and transport cost, the time-discounted net present value (NPV) of present and future harvests of fruits and latex alone was US\$6330 for the single hectare. This was more than 10 times the NPV of the site's timber potential, and more than double the value for converted land uses found in other Amazon studies. The authors concluded, "[t]hese data indicate that tropical forests are worth considerably more than has been previously assumed, and that the actual market benefits of timber are very small relative to those of nonwood resources" (Peters et al. 1989: 655). Some precautions were taken, though, by referring to the specific data set and by adding that "not every hectare of tropical forest will have the same market value as our plot" (Peters et al. 1989: 656). However, after noting a few of these problems, they still went on to state their belief that "the NPVs calculated in this study provide a useful economic benchmark for comparing alternative land use practices and management options for Amazonian forests." Our intention here is not to deride this study as an especially poor one. Rather, we seek to show how, without adequate attention to the details, even the best known studies may lead to misguided actions.

The study of Peters et al. (1989) has already been the target of a scattered academic critique (e.g., Godoy 1992, Pendleton 1992, Pinedo-Vásquez et al. 1992, Chomitz and Kumari 1998). We believe that our account is the first summary of this critique. First, there are concerns about the specific method, e.g., objections to the underestimation of post-harvest losses and marketing costs of perishable NTFPs, and to the assumption of an infinite time horizon with a low discount rate $(5 \%)$ in a situation in which land tenure and market insecurities abound. Doubts were raised about the generality of results extrapolated from the chosen location and whether the density of fruit trees was typical for the Amazon forest. Aspects of the biological inventory also affect the estimated production values. Fruit harvesting in the targeted region usually involves the cutting of some trees (Wil de Jong, personal communication to D. Sheil, January 2001). In consequence, local composition of dioecious species is often biased toward male (non-fruit-bearing) trees. Such destructive harvesting also implies that the available per hectare harvest levels recorded at any time cannot be simply extrapolated as a yearly constant into an infinite future. In a related vein, Grimes et al. (1994) were concerned about the per species productivity estimates used by Peters et. al. (1989), and the potentially large biases that they may cause. Thus, Grimes et al. (1994) proposed that yield and harvesting costs should be assessed on a stem-bystem basis.

The economic assumptions of Peters et al. (1989) have been singled out for particularly serious criticism (e.g., Pendleton 1992). The site selected by Peters and colleagues, close to the sizeable Iquitos market, was extremely favorable for high NTFP values, because of very low transport costs. Furthermore, the scaling up of these per hectare results to larger areas by simple multiplication is misleading. Local markets have elastic prices; hence, unit prices and extraction revenues must fall vis-à-vis a potentially increased supply of forest products (e.g., Smith et al. 1998).

Finally, Peters et al. (1989) looked at potential values based on inventories. Other studies (e.g., Padoch and de Jong 1989) have emphasized that realized production is generally much lower (also reviewed in Godoy et al. 1993). Some intuitive questions regarding the conclusions of Peters et al. (1989) are: Why don't local people actually derive these high potential incomes, and why isn't land covered by tropical forests traded at anywhere near the stipulated NPV of US\$6330/ha? This raises tacit doubts about the participatory dimension of the valuation: to what extent did the researchers actually consult local people and understand their costs and benefits, their context and motives for choosing among livelihood and land use options?

Quantitative literature reviews, such as Godoy et al. 
(1993) or Lampietti and Dixon (1995), exhibit the Peters et al. (1989) results as an "outlier," greatly exceeding most values reported in other tropical forest studies. For example, Pinedo-Vásquez et al. (1992) found in a similar study for San Rafael, also in the Peruvian Amazon, NTFP per hectare extraction values of barely 6\% of those in Peters et al. (1989). Despite this, the high per hectare value of Peters et al. (1989) has, in some cases, been uncritically transferred to settings such as the Ecuadorian Amazon, despite vast differences in biophysical and economic contexts (Acosta 1994). Other studies of similarly restricted and favourable scenarios soon followed that of Peters et al., however, further fuelling a growing but fragile optimism about NTFP extraction values (Anderson and Jardim 1989, Anderson et al. 1991, Anderson and Ioris 1992).

The Peters et al. (1989) study found an audience, searching for sustainable development options, that desperately wanted to discover that NTFP extraction from tropical forests was economically competitive (Panayotou and Ashton 1992). The article's success was also attributable to the marketing of the message: a concise note with clear policy implications, published in a highly respected journal. Certainly, some precautions were taken, but there was no space for a thorough discussion of potential caveats. Social obstacles to the realization of potential forest values were generally ignored. There was little attempt to clarify the many factors affecting the specific results from the single study area, although this would have better equipped the reader to examine the conclusions with respect to other sites. Standing tropical forests can provide large incomes through sustainable NTFP extraction was not exactly the published message, but it was nonetheless the message that made its way into forestry and conservation circles. Despite a current awareness in most expert circles that the original study was flawed, it remains highly cited and is even reproduced in full in some recent texts (e.g., Owen and Unwin 1997).

\section{DOES IT MATTER?}

Science often steers a crooked path from paradigm to paradigm (Kuhn 1962), so it is reasonable to ask why it matters in this case. Did the Peters et al. (1989) study influence academic opinion? It is a citation classic, with 161 listed citations in academic journals between 1990 and January 2002 (ISI 2002, through Oxford University). There is no sign that the citation rate is declining (Fig. 1). Did it also have an impact on policy and decision makers in the world outside academia?

Fig. 1. Yearly citation of Peters et al. (1989) in peerreviewed journals up to the end of 2001. Over the entire period, the ISI database provides 160 records (an additional record for January 2002 is omitted).

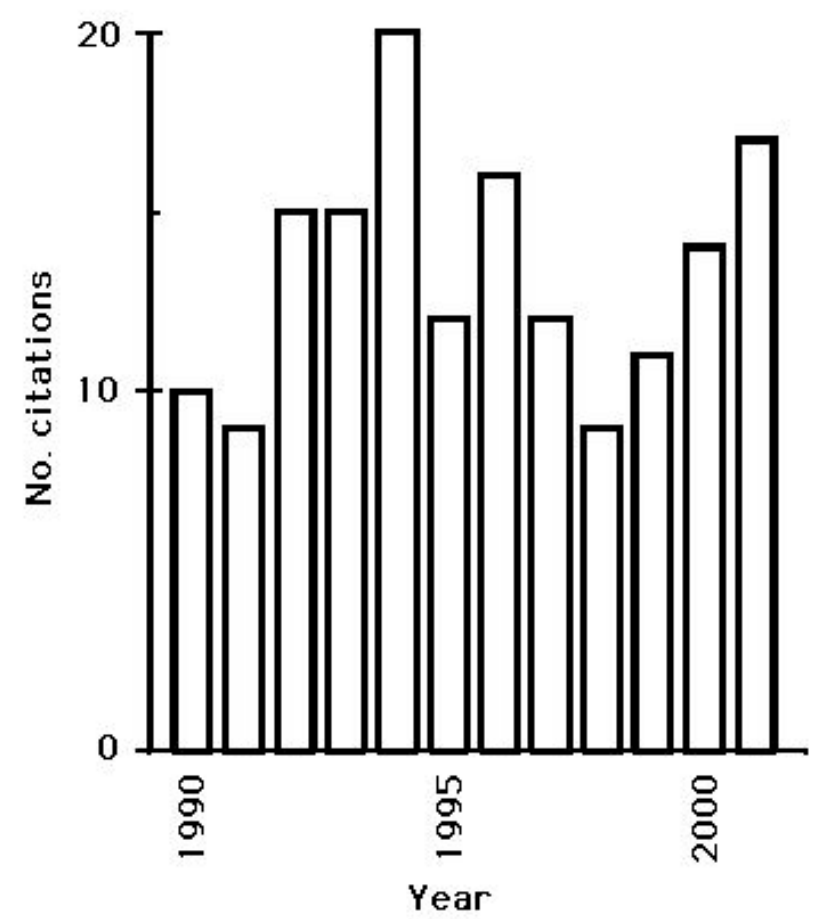

Spilsbury and Kaimowitz (2000) gathered information that strongly implies that it did. They conducted a poll in which a broad range of "forest policy experts" were required to list the publications they considered to have had "most impact". Peters et al. (1989) was ranked higher than any other research article by the 162 respondents. Some impacts were almost certainly positive; researchers benefited from a new-found donor interest in NTFP issues, and, ultimately, research has tried to set the record straight. However, there were also negative impacts. Spilsbury and Kaimowitz (2000) point out that the article gave "legitimacy to a particular policy perspective," and Peters et al. is singled out as showing "that work that is later criticized or discredited can nevertheless be extremely influential in ... shaping policy outcomes." Continuing, Spilsbury and Kaimowitz (2000) argue that, "Presumably, when policy narratives are misguided, overstated or incorrect, flawed development policies and practices follow." This 
assessment will be contentious, given the indirect evidence involved. Certainly, the Peters et al. article was part of a larger political movement, not the sole cause of it. But our thrust is that undesirable impacts could have been reduced, had the assumptions and uncertainties received greater emphasis.

So far, we have presented evidence that many academics continue to publish accounts referring to the Peters et al. article and, indeed, that many policy makers know of the original source and consider it to be highly influential. It is more difficult to assess the suggestion of Spilsbury and Kaimowitz (2000) that this may have led to "flawed development policies and practices." We have earlier noted the complex interplay of factors that are involved in any policylevel decision process (Keeley and Scoones 1999), and we know of no comparable cases in which any one factor can be tracked to gauge its influence within this context. We nonetheless feel confident in asserting that the article had negative impacts, for a number of reasons.

In our own experiences in the 1990s, we observed how numerous Integrated Conservation and Development Projects concerned with protecting forests and improving local livelihoods used the conclusions of Peters et al. (1989) to justify a considerable emphasis on NTFPs in project design and implementation. The main conservation organizations, such as IUCN (World Conservation Union), oriented their efforts in pursuit of an "NTFPs for conservation" paradigm. It is hard to overstate how those involved in tropical forest conservation in the 1990s were constrained by a political correctness that insisted nontimber products were essential in any solution (e.g., S. Wunder in Latin America and D. Sheil in East Africa, personal observation). We believe that excessive and uncritical expectations as to local income generation potential misdirected donor investments and led to unrealistic strategies. By generalizing flawed results, the international community probably lost time, resources, opportunities, and credibility in its campaigns against tropical forest destruction.

\section{GODOY ET AL. (2000)}

A decade after the publication of Peters et al. (1989), Ricardo Godoy and his colleagues (Godoy et al. 2000) also published a two-page "Letter to Nature" on forest economic values. This time, the conclusions were very different. Godoy et al. used a "doorstep accounting" approach to quantify the foods, medicinal products, construction, and craft materials brought into 32 Indian households in two villages in Honduras over 2.5 years. Based on this survey and using local market prices, the combined value of consumption and sale of forest goods was estimated at US\$6.06-7.50. The result was US\$17.79-23.72 per hectare per year, using purchasing power parity (PPP), an alternative to official exchange-rate conversion designed to better reflect price differences between countries (Costanza et al. 1997). This value is at the low end of previous forest value estimates.

Godoy et al. (2000) addressed many of the concerns that we have raised thus far. They examined actual instead of potential extraction values over a wholeforest area. They applied a longer study period and investigated a larger set of products. Subsistence uses were included, and the pricing mechanism was relatively sophisticated. However, although a great deal of information was squeezed into the short report, the authors' tentative conclusions are somewhat surprising:

1. low per hectare forest values may explain local forest conversion to other uses;

2. local people receive few forest benefits relative to outsiders; and

3. security values are slight.

The first conclusion is surprising because the report neither clarifies whether local people are clearing forests, nor explores their rationale for doing so (as we shall discuss). The second and third conclusions are also speculative, because the paper analyzes neither global (e.g., carbon), nor security values. Subsequently, two of the co-authors of Godoy et al. (2000) produced a detailed 382-page book that provides considerable background material on a broader series of studies in the same communities (Demmer and Overman 2001). They nonetheless stuck to the main conclusions of the original Nature study.

Forewarned by our appraisal of the Peters et al. (1989) article and its subsequent impact, we suspect that the perceived policy message of the conclusions of Godoy et al. (2000) will be: Standing tropical forests tend to provide low returns to local communities, or tropical forests can't pay for themselves. Although a qualification of the high-value paradigm of the early 1990 s is necessary, the pendulum may be swinging too far and too fast. 


\section{A CHECKLIST}

There are several useful reviews and discussions about valuation approaches and methods (e.g., Bingham et al. 1995, Adamowicz et al. 1997, Wollenberg 1998, Gram 2001; R. N. Byron, unpublished manuscript). Godoy and his colleagues have indeed authored some of the most practical (Godoy 1992, Godoy and Lubowski 1992, Godoy and Bawa 1993, Godoy et al.
1993). Our aim here is not to make an exhaustive review, but rather to show some specific pitfalls and concerns and highlight the need for caution. Our critique suggests that the Nature papers stand as examples of more general problems. In organizing our critique, we have identified a simple series of questions to provide a generic checklist that we will discuss further, returning to the Nature articles and other material (see Table 1).

Table 1. Checklist for a valuation study.

Main features of a valuation

Checklist questions

Objectives and definition

What are the objectives and alternative scenarios?

What is being valued and how? (What, where, when, and for whom?)

How are values defined and quantified (units, measurement, estimation, and calculation)?

Uncertainties

What are the uncertainties associated with these quantities, relationships, and sum values? This should consider:

a) omissions

b) sampling,

c) biases, and

d) other errors

Context dependence, extrapolation, and generality

Interpretations and worldviews
How can value variations be related to localities, times, and contexts within the local neighborhood?

To what extent can these values be related to other locations, times, and contexts?

How are the main results interpreted?

Have local explanations been examined?

How robust are the results to changes in assumptions?

Who's worldview is the study addressing?

\section{OBJECTIVES}

Value is not the inherent property of an entity: it is a measure of a relationship between a subject and the object of valuation within a context (time and place, or hypothetical scenario). These basic "terms of assessment" define and delimit the scope of each study and the sphere of any potential research conclusions. 
There is a fundamental distinction to be made between a valuation exercise that sets out to explain how choices are made by individual resource users and one that seeks to maximize community or societal wellbeing. Explaining how a user weighs alternative options is largely a matter of understanding incentives, the actions themselves, and the rules and perceptions that relate to them. A societal perspective requires a broader approach, usually some type of social costbenefit analysis, and is necessarily a normative exercise because it involves judgments about which outcomes are socially preferrable (e.g., Costanza and Folke 1997). The two approaches employ different attitudes to the views of local actors. For example, a government may judge that some local views are "irrational" or "poorly informed," although these remain the views that govern the choices of the locals themselves. Local people and technical experts may have very different views leading to very different results. If the bases of local choices are being explored, as would appear to be the case in the Nature studies, information developed by technical experts from outside may not be as relevant as they themselves may choose to argue.

What is appropriate thus depends on the objective of the study (see Wollenberg 1998). Both of the Nature papers aimed to value standing forests on a marketdriven dollars per unit area basis, in terms of forest products, and, implicitly or explicitly, to compare this with other land uses. Peters et al. (1989) valued a series of plant products sold on regional markets, based on current market prices. Godoy et al. (2000) estimated actual extraction of animal and plant commodities that are sold or used locally. The objective of both studies appears to be an assessment of forest value from a local perspective vis-à-vis alternative uses, or at least this is the main emphasis of their conclusions.

It is undeniable that local people in much of the tropics currently replace forests with other land uses, and that economic returns often play a significant role in their decision. However, we argue that neither study provides much insight into choices concerning forest clearance. Both studies confuse local perceptions with a limited economic statement of value that involves the judgement and choices of a third party (the researchers). Here, we will consider what else would be required to develop a better understanding of the choices involved, and will draw on the literature and our own experiences for illustration.

\section{UNCERTAINTIES}

\section{Omissions}

Even the best forest valuation study cannot quantify all potential values; choices have to be made. In Peters et al. (1989), omissions of some products (e.g., medicinal plants and wildlife) appear of little consequence, given the high value already obtained. In Godoy et al. (2000), however, an examination of potential omissions is required before a general conclusion of "very low value" can be accepted. We will consider whether these omissions matter, and propose a simple checklist approach.

Forest products: A "doorstep approach" (c.f. Godoy et al. 2000) would be difficult to apply to those forest peoples who spend considerable time away from their "formal" village, a common system in some forestbased cultures (e.g., Colfer et al. 1997). Consumption away from the settlement often appears to be important (Gram 2001; D. Sheil and S. Wunder, personal observation; Patricia Shanley, personal communication). In some cultures, children, in particular, may gather fruits or hunt small animals and eat them away from home (Colfer et al. 1997). Domestic animals may also gain considerable fodder from forest lands.

Nutritional values: A counterargument to the previous point is that what is consumed during a collecting trip produces no extra net value, and is thus a "marginal cost of extraction." However, this ignores a qualitative dimension of nutrition: many forestdwelling people derive the bulk of their protein consumption from the forest (Colfer et al. 1997). Returning home with a full stomach and gaining a more balanced diet from multiple forest products, may be important in some contexts.

Construction and timber: A problem with the "doorstep accounting" method is that the doorstep itself may be neglected. Most forest-dwelling people place importance on the materials that they need to build their homes, boats, etc. Such wood is neither collected regularly nor carried over any "doorstep," but nonetheless can be highly valued.

Insurance values: In many forest frontier regions, farming is risky. Forest products provide insurance against potential crises, providing food and saleable products. The study of Godoy et al. (2000) has not seen any such crises, but even so, it argues that "one 
must be cautious before attaching too much weight to the insurance value of the forest." However, from the perspective of the risk-averse forest dweller, the opposite view appears much more compelling: outsiders should be cautious not to overlook insurance values.

Forests and the poor: One often finds within villages a disproportionately high reliance on open-access resources by the disadvantaged (e.g., Cavendish 1997, Jodha 2000). This poverty aspect may be essential to a subgroup of local stakeholders and to external agencies considering forest value and people's dependencies.

Hydrology: Forests are often associated with various hydrological values (e.g., Ruitenbeek 1990). Calder (1998) lists proposed forest benefits as higher rainfall, greater runoff, regulated flow, less erosion, less flood hazard, and higher water quality. However, the hydrological consequences of conversion remain poorly understood (Bruijnzeel 1990). Calder (1998) finds that evidence for and against each of these values may be little more than "myths and folklore," but remains confident that some effects (e.g., water quality) are real. Yet, many values are site specific and depend much on the alternative land use being compared. The watershed values of forests are contentious (c.f., Chomitz and Kumari 1998), but should not be disregarded (Calder 1998).

Protection: Physical protection values of forests can be considerable in some areas, e.g., providing flood protection and stabilizing slopes. Again, values are site specific, and quantifying them against credible alternatives proves difficult (e.g., Aylward and Barbier 1992).

Other externalities: There can be many local advantages and disadvantages in having a forest nearby. Forests often create a milder, moister local climate, which may benefit certain crops (e.g., tea; Hamilton and Bensted-Smith 1989) and human health (e.g., limiting the range of disease vectors in tropical highlands; Watson et al. 1996, Lindsay et al. 1998, Craig et al. 1999). Forests can also provide ecological services such as pollinators required for crops and fruit gardens (e.g., bats required for pollination in the major durian fruit trade in Southeast Asia; Salafsky 1995). Research continues to underline just how little is really known about the true importance and maintenance of services such as pollination (Gordon et al. 1990, Roubik 2002). Although potentially contributing to well-being, such factors cannot be motivations for those who do not know or recognize them. Conversely, potential problems of having a forest nearby include crop-raiding by forest animals, certain health risks (e.g., yellow fever, blackflies, tsetse). Even comfort can be affected. In the Andes, some local people favor forest-clearing, in part, to reduce the discomfort of high humidity (Wunder 1996).

Irreversible options: Natural forest can be converted to other land uses, but other land uses cannot so readily be converted back to forests, at least not forests that provide the original range of goods and services. This raises a complexity of economic concerns about reversibility and option values (e.g., Fisher and Hanemann 1990, Linddal 1993). Studies can give attention to whether forest conversion, or other interventions result in irreversible losses of, or impaired access to, some local livelihood options.

Our list of omissions is a general catalogue of potentially important factors. We do not suggest that each is relevant in every case. For instance, it may be that, in many locations, converted land uses provide equivalent or satisfactory hydrological and protection benefits, or that many people derive little nutritional value from wild forest produce. However, in some cases, these aspects may include the principle values of the forest. Ideally, any valuation study would take care to include those aspects perceived to be most relevant. What should be valued depends on the nature of the investigation: for example, it would not be appropriate to value the scientifically authenticated links between forest cover and services such as hydrology or protection if the valuation refers to local perceptions of these, and local people do not actually perceive these benefits. We suggest that each valuation study should ensure that the choice of what is included and what is excluded should be transparent to the reader.

\section{Sampling}

A vast body of literature on sampling underlines some inescapable fundamentals (e.g., Cochran 1977, FAO 1981, Thompson 1992). For example, a single plot, such as used by Peters et al. (1989), is always inadequate as an objective basis for generalization. Objective replication in space is required for spatial generalization, whereas replication in time is similarly required for formal temporal generalization. Godoy et al. (2000) investigate two villages, thus providing a minimal degree of replication, but it is not clear by 
what criteria the villages were chosen among the universe of possible villages.

Godoy et al. (2000) circumvent plot-based sampling by assessing a complete catchment for each village. A $3-\mathrm{km}$ foraging radius defines this area. However, research in all three tropical continents indicates that people often collect forest resources from remoter areas. In particular, game hunting areas are not neatly delimited, and hunters will benefit from animals arriving from much larger tracts of productive source habitat (Bodmer et al. 1994). With some migratory species, such as wild pigs, ranges can be considerable (Caldecott 1988, 1991). Enlarging the catchment area may reduce average per hectare values, but may raise per household returns.

Godoy et al. (2000) address temporal uncertainty by conducting their study over 2.5 years. We already questioned the ability to fully capture insurance and construction timber values over this time period. As demonstrated by Gram (2001), different methods such as focal follows, user's notebook registration, and interviews with different recall periods all have uncertainties attached. Additional uncertainties persist in both biological and economic long-term processes (e.g., the studies in Boomgaard et al. 1997). Godoy et al. note that the value of goods from one of their communities (Krausirpe) dropped inexplicably by onethird in two years. Ongoing research, already spanning 10 years in Pará State (Brazilian Amazon), indicates that phenological cycles can imply large year-to-year fluctuations in fruit collection, dropping to zero for some seasons (P. Shanley, CIFOR, personal communication). Similar patterns are found in other tropical regions, e.g., for the illipe nuts exported from Borneo (Curran et al. 1999). Understanding long-term variation and uncertainty may itself be insightful in some cases. Robust collection values require long assessment periods.

\section{Strategic biases}

Numerous biases can arise, some of which have already been mentioned. We will focus here on one neglected subset: strategic community behavior. Community members may react in various ways to the perceived "opportunities" and "threats" of being researched. People may seek to bias their recorded forest uses upward so as to be better recognized, e.g., by being seen to be using a larger area, or collecting more produce than usual, or at least ensuring that it crosses the "right" doorstep. Deception aside, experience shows that villagers will spontaneously collect all kinds of produce to show to the "interested outsiders," to entertain and provide hospitality, and even to feed the extra mouths now eating in the village.

A downward bias may arise from the secrecy surrounding taboos, illegal activities, shame, conflicting uses, or jealousies. There may be protected knowledge (e.g., with medicinal plants), or a general suspicion about how "the outsiders" will use the information. Strictly protected forests often provide numerous, if technically unlawful, benefits to local communities, but these are notoriously difficult to measure.

Researchers need to be aware of their own subtle influence. In the Dayak communities of Kalimantan, one of us (D. Sheil) has seen locals hide pig products from some Islamic researchers to "be polite." In other cases, freshly caught cage birds are hidden from outsiders who showed concern. Such biases are rarely mentioned, let alone examined, in quantified studies. The best practical approach would be to live with local communities for adequate periods for the research to become "normal" and for the researchers to dispel suspicions and understand and guard against distortions.

\section{CONTEXT AND EXTRAPOLATION}

Few journal readers wish to know the local value of specific forest area $X$ to community $Y$ in country $Z$. What will be of interest is the ability to shed light on more general patterns. We are concerned with assisting readers who seek to understand the wider applicability and implications of local results and conclusions. It is a matter not only of detailing methods, but also of providing context. The reader should be enabled to recognize a minimum set of spatial, biological, and social characteristics and constraints. As part of our "checklist approach," it is useful to spell out those that we consider most important (see Table 2).

In principle, each contextual factor might influence the broader interpretation of the economic values found. It may also provide insight on which to base decisions concerning resource management, and to relate the results to other forest settings.

Spatial aspects: Forests are a diverse combination of biotic and abiotic factors that are experienced in 
different ways by different people. Products and services are unevenly distributed. For a given user, many subsistence demands (e.g., fuel wood) may be met in accessible areas, whereas others (e.g., wildlife) require wider areas or access to specific sites. Average per hectare values cannot capture the range and pattern of values as perceived by local users. Not all values are interchangeable across space. When different products are exclusively localized in different parts of the landscape, such spatial variety itself has importance (Campbell et al. 1997).

Table 2. Checklist to place studies within a wider context.

How is the local production integrated into the market economy? (e.g., distance to markets, navigable rivers, roads, transport costs, middlemen margins).

What type of forest are people using? What activities or historical events may have influenced the vegetation? Is it highly manipulated or near-natural?

What main products are extracted? What are their marketing characteristics (e.g., perishability, local valueadded or processing, demand elasticities)? Are some products dominant?

Are the products planted, tended, or wild? Is harvesting regulated by local or government interventions (taxes, incentives, controls)? Who owns, tends, guards, collects, and buys? What are the norms of behavior? What determines/constrains production (land, labor, skills, credit, technology, market access, tenure, conflicts, etc.)?

What are the local skills, views, and dispositions, including the potentially diverse cultural and institutional factors that influence preferences, motivations, and the ability to act upon them?

Value denominator: Local people's deforestation tends to be a gradual process that reflects marginal choices about investing efforts in small pieces of land: whether and where to clear. Such implementation depends on, inter alia, local availability of land, labor, skills, and technologies (Kaimowitz and Angelsen 1998). Reporting per hectare values alone, as in the Nature articles, implicitly assumes that land as a production factor is scarce and that its alternative use represents a decisive choice for the welfare of local people.
There is evidence that choices are often constrained by returns on labor rather than on land. For instance, Melnyk and Bell (1996) studied two villages of the forest-dwelling Huottuja Amerindians in a remote forest area of Amazonas State, southern Venezuela, and found per hectare forest extraction values in the extremely low range of US\$ 0.46-1.01. However, annual per household values were as high as US\$1902-4696. This is because they used the forest in an extremely extensive way, underexploiting the per hectare potential for harvesting NTFPs, but optimizing labor efforts (Melnyk and Bell 1996:470-471). Labor inputs may be difficult to measure comprehensively, but per household values may provide a reasonable proxy for labor returns in production systems dominated by family labor.

To illustrate the significance of the choice of "denominator unit," we have recalculated the per hectare figures of Godoy et al. (2000) back to per household terms; i.e., the units they were created in (see Table 3 using the simple calculation: ha value $\mathrm{x}$ total area divided by number of households). We did so circumventing a currency error in Table 1 of Godoy et al. (2000), which had accidentally inflated forest extraction values. Godoy et al. (2000:62) reported: "During 11 months of 1996, people from Krausirpe sold forest goods worth US\$91,041." However, a consistency check and subsequent consultations with the authors revealed that the figure was in lempiras (the Honduran currency), corresponding to US\$7781 (official rate) or US\$31,072 (PPP rates). The wealth difference between the two villages disappears when we look at per household values. The 1996 extraction per household in "rich" Krausirpe (US\$1399) is lower than the 1995 figure in "poor" Yapuwas (US\$1494), and only 3\% higher than the 1996 Yapuwas figure.

We know too little about the context to make an extensive interpretation of this finding. However, the near equivalence of the estimates bolsters our suspicion that forest returns in each village are more limited by labor than by forest land. Unless the two communities' forests are different in terms of available products, this would also suggest that the forests in the Yapuwas catchment (and maybe in both villages) were underutilized and have potential to yield higher values.

Thus, in an extremely forest- and land-abundant environment where people care little about alternative forest uses, but much about how to allocate their labor, is the conclusion of Godoy et al. (2000) that "the low economic value of the rain forest to local people 
explains why they might clear forest for other uses" relevant? This may or may not be the case (e.g., see Godoy et al. 1997). First, we need to evaluate what productive alternatives are feasible (e.g., agriculture, ranching), and locally desirable. Land valuation studies also may be proposed in the context of seeking financial statements for compensation or benefit transfers, generally considered on an area basis. Second, forest-clearing is, in itself, a highly labordemanding activity, which may not be worth the effort. It may be that extracting rich forest resources provides a higher return to scarce labor than, for instance, clearing forest for agriculture.

Table 3. Comparison of per hectare and per household forest extraction values derived from Godoy et al. (2000:62-63 and personal communication).

\begin{tabular}{|c|c|c|c|c|c|c|c|c|c|c|}
\hline \multirow[t]{2}{*}{ Village } & \multirow{2}{*}{$\begin{array}{l}\text { No. } \\
\text { house- } \\
\text { holds }\end{array}$} & \multirow{2}{*}{$\begin{array}{l}\text { Catch- } \\
\text { ment size } \\
\text { (ha) }\end{array}$} & \multirow{2}{*}{$\begin{array}{l}\text { Implied } \\
\text { wealth } \\
\text { status }\end{array}$} & \multirow[t]{2}{*}{ Unit derived $^{\mathrm{a}}$} & \multicolumn{2}{|c|}{ US\$ per ha per yr } & \multicolumn{2}{|c|}{ Total value (\$/yr) } & \multicolumn{2}{|c|}{$\begin{array}{l}\text { Household value } \\
\text { (US\$/yr) }\end{array}$} \\
\hline & & & & & 1995 & 1996 & 1995 & 1996 & 1995 & 1996 \\
\hline \multirow[t]{2}{*}{ Yapuwas } & 16 & 2779 & "Poor" & PPP & 8.6 & 7.8 & 23,900 & 21,676 & 1494 & 1355 \\
\hline & & & & Exchange & 2.7 & 2.6 & 7375 & 5428 & 498 & 339 \\
\hline \multirow[t]{2}{*}{ Krausirpe } & 53 & 2676 & "Rich" & PPP & 38.7 & 27.7 & 103,570 & 74,132 & 1954 & 1399 \\
\hline & & & & Exchange & 12.2 & 9.4 & 34,560 & 18,565 & 652 & 350 \\
\hline
\end{tabular}

${ }^{a}$ Conversion rates, lempiras per US\$, are: PPP $(1995,3.16$; 1996, 2.93). Exchange rates are 9.47 for 1995 and 11.70 for 1996.

\section{INTERPRETATIONS AND WORLDVIEWS}

Our discussion has thus far accepted the basic concept of economic valuation studies as a basis for examining land use decisions of local peoples. Much has already been said and debated about the relationships between finance, economics, and other values, and the meaning of any perspective chosen; it is probably pragmatic to avoid this semantic quagmire as far as possible. However, it is important in assessing economic methods to stand back and recognize the role that noneconomic values play for many forest-dwelling communities. As summarized by Wollenberg (1998): "If the purpose is to demonstrate villagers' valuation of forest products, there is ample evidence that forest products are valued along diverse dimensions, including nutritional value, economic security, environmental services or spiritual value that bear no relation to market price."

The literature on cultural, spiritual, and heritage "values" of forests (Davidson 1990, Henning 1998) underlines that these can exert a strong influence on local preferences and "well-being" (e.g., Schroeder 1989). Many cultural values have been associated with forests in wealthy societies (Loomis 2000), and are not zero in poorer societies (Garrod and Willis 1997). An illustrative example is the cultural value often attached to hunting in the forest. Yet, such values may also be intrinsically negative, e.g., for immigrant settlers who fear forests, or elites who associate forest dependence with either "backwardness" or anarchy and a place that "afford[s] shelter to those at odds with the established power" (Westoby 1989).

To understand decisions about forest land use, we also need to have a clear perception of the institutional context: what are the roles of the individual, the household, and village institutions (formal and informal)? What are their mechanisms, rights, and obligations? Institutional factors can determine how different stakeholders regard natural resources. It has often been claimed that open access and insecure land tenure accelerate degradation and/or deforestation (Southgate 1990, Hyde et al. 1996). Revealing the subtleties of power play between stakeholders can be 
crucial. For example it is recognized that some social and biophysical pre-conditions may be more favorable to collective forest management than others (Ostrom 1999).

If we wish to address the values of landscape to local peoples, we also need to gauge their attitudes to it (e.g., Adamowicz et al. 1997). Local attitudes and norms can also influence land use significantly. For example, the Dayak people of Borneo have never taken to rearing cattle, not because of low profits, but because of cultural predispositions regarding animal rearing (Colfer et al. 1997); similar considerations apply to forest-dwelling people in Central Africa. Yet, the Dayak people in Borneo place a high importance on wild forest pigs, although the many Muslim immigrants see them only as a major pest (Colfer et al. 1997).

To what degree should we expect any analytical procedure to reflect the choices of any given community with their own norms and customs? Numerous reviews highlight the lack of universally acceptable approaches (e.g., Amin 1992, Funtowicz and Ravetz 1994, Jenkins 1996, 1998, Henning 1998, Wollenberg 1998, Gatzweiler 1999, Soderbaum 1999, Daily et al. 2000). Most importantly, a simple formulation process and table of measured variables may not provide a one-size-fits-all procedure. The experiences, preferences, and idiosyncrasies of any individual or group can be decisive, but may only be recognized if they are sought out.

Local communities are not laboratory mice; they can be asked to explain and discuss their motivations, preferences, and choices. This has pitfalls of its own (e.g., Bradburn et al. 1987, Nemarundwe and Richards 2002), and is best approached using a range of methods and crosschecks. A key point is that economic valuation figures, however carefully generated, will never provide a complete explanation for local patterns of behavior. The extent to which they are an adequate or sufficient explanation remains open to debate.

One of us (D. Sheil) is currently involved in a program of research in Kalimantan (Indonesian Borneo) that tries to identify and characterize the relationship between community members and resources in the forest landscape. A broad suite of wide-ranging exercises is undertaken to identify what actually matters locally. The methods are diverse and include community meetings and mapping exercises, various interviews on needs and uses, and a broad range of field-based site evaluations (Sheil et al. 2002, in press). Quantitative weightings of "perceived importance" are given to various types of sites, resources, species, and classes of use, management rules and taboos are documented, aspirations and concerns are described, and preferences for farming, hunting, etc. are elicited. This is not the place to develop a full account of methods and results, but initial results provide a rich source of insight into local perceptions, and highlight the importance of unlogged high forests in the daily lives and aspirations of indigenous communities (Sheil 2002). Once these local priorities are better appreciated, the need for such a diagnosis becomes striking in many aspects of outsider-led activities. Such techniques can be particularly useful when seeking to include less vocal and less powerful stakeholders. Whether such studies are termed "economic" or not is a matter of semantics. The point is that they can be used to direct or complement studies that use economic approaches, or perhaps, more importantly, to support any activities that seek to address the concerns of local communities with regard to the landscapes that they inhabit.

\section{CONCLUSION}

We have examined Peters et al. (1989) and Godoy et al. (2000) for the purpose of illuminating general problems with forest valuation studies. The flaws in the first study are clear enough with hindsight. Having demonstrated that this is more than an academic argument of details, we have shown that Godoy et al. (2000) pose distinct, yet similar, risks in contributing to a new "policy narrative" that, although widely welcomed, may ultimately be no less misleading. We structured this argument through a series of questions that should be asked about any landscape valuation study. These concern the objectives and definition of the study, the uncertainties involved (i.e., omissions, sampling concerns, methodological biases, and errors), contexts, extrapolation, generality, and ultimate interpretation. The legitimacy of any conclusions depends on the scope and objective of the study as well as its methods and assumptions. If the motivations and choices of local people are the primary focus, their views and interpretations need to be understood, and can and should be accessed directly.

In the broader debate about tropical land uses, it is now fashionable to spice arguments about forest conservation or conversion with estimated per hectare 
economic returns. These estimates can arguably provide a useful "bottom line" to studies of forest values and, in this sense, they may be useful, but there are important caveats. Our discussion of the Peters et al. and Godoy et al. articles has provided some examples. Generalizing these lessons emphasizes that, first, one needs suitable methods, which must be reported in a way that is sufficiently transparent to indicate weaknesses. Second, numerous assumptions and details lie behind any per hectare estimates, and these need to be examined. Third, per hectare returns are only one of a series of economic indicators, and may have limited relevance for resource-use decisions, especially by local communities. Fourth, forests offer many benefits that are difficult to grasp in monetary terms. It remains contentious, at best, whether everything people "value" in the broader sense can or should be "priced" in the narrow quantitative sense. It is essential to consult local people on what matters to them or on the choices that they would make in different scenarios.

Thus, our main criticism is that many studies are focused on quantifying the per hectare economic value of forest extraction without questioning its relevance. As we have argued, the broader contexts and motivations for changing land use require more understanding. Such neglect is a particular shame when intensive, long-term research must have provided a wealth of relevant information beyond what can be provided in a simple one-dimensional statement of estimated value.

Valuation studies that address local needs or motivations should integrate a participatory diagnosis of local preferences. Instead of focusing exclusively on pre-identified methods (e.g., user's notebooks) and criteria (e.g., per hectare values), we recommend a more flexible approach. The need is to better clarify what actually determines local behavior and decision making, and even what influences local perceptions of well-being.

Our review of the two Nature articles also highlights the larger questions as to the extent that compact presentation of research results can do justice to complex and site-specific research topics, and whether decision makers reading it are enabled to grasp the underlying interplay of factors. More comprehensive valuation case studies are still required, but these are likely to appeal primarily to an academic audience. We are still faced with the inherent paradox of requiring increasingly detailed and sophisticated data collections to understand the implicit valuation choices that local people are making as part of their day-to-day lives.

How desirable is it that researchers deliver highly simplified, yet confident, "executive-style" messages that policy makers readily absorb? Attractive speculations and generalizations can easily be misinterpreted or even abused. In the contentious fields of forest conversion and rights, such risks have real consequences. There is probably little that can be done other than to call attention to the problem and encourage greater caution by policy makers and scientists alike. We must strive to ensure that only balanced and substantiated messages are given, and that conclusions are well founded and not overstated. Although detailed comprehensive presentations remain undesirable to decision makers, a cautious and responsible framing and interpretation of forest valuation studies is essential.

Responses to this article can be read online at: http://www.consecol.org/vol6/iss2/art9/responses/index.html

\section{Acknowledgments:}

We are grateful for constructive comments on earlier documents from Ricardo Godoy, David Wilkie, Han Overman, Adoni Cubas, Glenda Cubas, Josefien Demmer, Kendra McSweeney, Nicholas Brokaw, Charles Peters, Patricia Shanley, Robert Nasi, Lini (Eva) Wollenberg, Wil de Jong, Brook Johnson, David Kaimowitz, Carl Folke, and reviewers. Thanks also to Kim (Meilinda) Wan, Indah Susilanasari, Nining Liswanti, and the CIFOR library staff for assistance in document preparation and literature access. Roger Mills (Department of Plant Sciences, Oxford) kindly provided the citation statistics. D. Sheil's work in Kalimantan has been supported by the International Tropical Timber Organization (ITTO) through the project "Forest, Science and Sustainability: The Bulungan Model Forest" PD 12/97 Rev. I (F). S. Wunder's forest valuation work in Brazil has been funded by the Danish Agency for Development Assistance (Danida).

\section{LITERATURE CITED}

Acosta, J. A. 1994. Elements for calculating the value of biological diversity losses: the case of oil exploitation in the Cuyabeno Reserve in the Ecuadorian Amazon region. Pages 205-219 in M. Munasinghe and J. McNeely, editors. Protected area economics and policy. Linking conservation and sustainable development. IUCN (International Union 
for the Conservation of Nature) and The World Bank, Washington D.C., USA.

Adamowicz, W., M. Luckert, and M. Veeman. 1997. Issues in using valuation techniques cross-culturally: three cases in Zimbabwe using contingent valuation, observed behaviour and derived demand techniques. Commonwealth Forestry Review 76:194-197.

Amin, S. 1992. Can environmental problems be subject to economic calculations? World Development 20:523-530.

Anderson, A. B., and E. M. Ioris. 1992. The logic of extraction: resource management and income generation by extractive producers in the Amazon estuary. Pages 175-199 in K. Redford and C. Padoch, editors. Conservation of neotropical forests: working from traditional resource use. Columbia University Press, New York, New York, USA.

Anderson, A. B., and M. A. G. Jardim. 1989. Costs and benefits of floodplain forest management by rural inhabitants in the Amazon estuary: a case study of Açaí palm production. Pages 114-129 in J. O. Browder, editor. Fragile lands of Latin America: strategies for sustainable development. Westview Press, Boulder, Colorado, USA.

Anderson, A. B., P. H. May, and M. J. Balick. 1991. The subsidy from nature: palm forests, peasantry, and development on the Amazon frontier. Columbia University Press, New York, New York, USA.

Aylward, B., and E. B. Barbier. 1992. Valuing environmental functions in developing countries. Biodiversity and Conservation 1:34-50.

Bingham, G., R. Bishop, M. Brody, D. Bromley, E. Clark, W. Cooper, R. Costanza, T. Hale, G. Hayden, S. Kellert, R. Norgaard, B. Norton, J. Payne, C. Russell, and G. Suter. 1995. Issues in ecosystem valuation: improving information for decision making. Ecological Economics 14:73-90.

Bodmer, R. E., T. G. Fang, I. L. Moya, and R. Gill. 1994. Managing wildlife to conserve Amazonian forests: population biology and economic considerations of game hunting. Biological Conservation 67:29-35.

Boomgaard, P., F. Colombijn, and D. Henley, editors. 1997. Paper landscapes: explorations in the environmental history of Indonesia. KITLV Press, Leiden, The Netherlands.

Bradburn, N. M., L. J. Rips, and S. K. Shevell. 1987. Answering autobiographical questions: the impact of memory and inference on surveys. Science 236:157-161.

Bruijnzeel, L. A. 1990. Hydrology of moist tropical forests and effects of conversion: a state of the knowledge review. Netherlands Committee for the International Hydrological Programme of UNESCO, Amsterdam, The Netherlands.

Caldecott, J. 1988. Hunting and wildlife management in
Sarawak. Tropical Forest Programme, IUCN (International Union for the Conservation of Nature), Gland, Switzerland.

Caldecott, J. 1991. Eruptions and migrations of bearded pig populations. Frädrich-Jubiläumsband 18:233-243.

Calder, I. R. 1998. Water-resource and land-use issues. SWIM Paper 3. International Water Management Institute, Colombo, Sri Lanka.

Campbell, B. M., M. Luckert, and I. Scoones. 1997. Local-level valuation of savanna resources: a case study from Zimbabwe. Economic Botany 51(1):59-77.

Cavendish, W. 1997. The economics of natural resource utilisation by communal area farmers of Zimbabwe. Dissertation. University of Oxford, Oxford, UK.

Chomitz, K. M., and K. Kumari. 1998. The domestic benefits of tropical forests: a critical review. The World Bank Research Observer 13(1).

Cochran, W. G. 1977. Sampling techniques. Third edition. Wiley, New York, New York, USA.

Cohen, M. D., J. D. March, and J. P. Olsen. 1972. A garbage can model of organizational choice. Administrative Science Quarterly 17:1-25.

Colfer, C. J., N. Peluso, and C. S. Chung. 1997. Beyond slash and burn. New York Botanical Garden, New York, New York, USA.

Costanza, R., R. d'Arge, R. de Groot, S. Farber, M. Grasso, B. Hannon, K. Limburg, S. Naeem, R. V. O'Neill, J. Paruelo, R. G. Raskin, P. Sutton, and M. van den Belt. 1997. The value of the world's ecosystem services and natural capital. Nature 387:253-260.

Costanza, R., and C. Folke. 1997. Valuing ecosystem services with efficiency, fairness and sustainability as goals. Pages 49-68 in G. Daily, editor. Nature's services: societal dependence on natural ecosystems. Island Press, Washington, D.C., USA.

Craig, M. H., R. W. Snow, and D. le Sueur. 1999. A climate-based distribution model of malaria transmission in Sub-Saharan Africa. Parasitology Today 15:105.

Curran, L. M., I. Caniago, G. D. Paoli, D. Astianti, M. Kusneti, M. Leighton, C. E. Nirarita, and H. Haeruman. 1999. Impact of El Niño and logging on canopy tree recruitment in Borneo. Science 286:2184-2188.

Daily, G., T. Söderqvist, S. Aniyar, K. Arrow, P. Dasgupta, P.R. Ehrlich, C. Folke, A. M. Jansson, B. O. Jansson, N. Kautsky, S. Levin, J. Lubchenco, K. G. Mäler, D. Simpson, D. Starrett, D. Tilman, and B. Walker. 2000. The value of nature and the nature of value? Science 289:395-396.

Davidson, J. 1990. Values and uses: seeing the forest 
through different eyes. Pages 124-132 in L. J. Webb and J. Kikkawa, editors. Australian tropical rainforests: science, values, meaning. CSIRO (Commonwealth Scientific and Indusrial Research Organization), Melbourne, Australia.

Demmer, J., and H. Overman. 2001. Indigenous people conserving the rain forest? The effect of wealth and markets on the economic behaviour of Tawahka Amerindians in Honduras. Tropenbos series 19. Tropenbos International, Wageningen, The Netherlands.

Fairhead, J., and M. Leach. 1995. False forest history, complicit social analysis: rethinking some West African environmental narratives. World Development 23:10231035.

FAO (United Nations Food and Agriculture Organization). 1981. Manual of forest inventory. Forestry Paper 27, FAO, Rome, Italy.

Fisher, A., and W. Hanemann. 1990. Option value: theory and measurement. European Review of Agricultural Economics 17:167-180.

Funtowicz, S. O., and J. R. Ravetz. 1994. The worth of a songbird: ecological economics as a post-normal science. Ecological Economics 10:197-207.

Garrett, J. L., and Y. Islam. 1988. Policy research and the policy process: do the twain ever meet? International Institute for Environment and Development (IIED) Gatekeeper Series Number 74. London, UK.

Garrod, G. D., and K. G. Willis. 1997. The recreational value of tropical forests in Malaysia. Journal of World Forest Resource Management 8:183-201.

Gatzweiler, F. W. 1999. Contingent valuation of environmental functions: a participatory method to estimate the total value of rubber forest gardens in West Kalimantan. Quarterly Journal of International Agriculture 38:128-139.

Godoy, R. 1992. Some organizing principles in the valuation of tropical forests. Forest Ecology and Management 50:174-175.

Godoy, R., and R. Lubowski. 1992. Guidelines for the economic valuation of non timber tropical forest products. Current Anthropology 33:423-433.

Godoy, R., R. Lubowski, and A. Markandaya. 1993. A method for the economic valuation of non-timber forest products. Economic Botany 47:220-233.

Godoy, R., K. O’Neill, S. Groff, P. Kositshack, A. Cubas, J. Demmer, K. McSweeney, J. Overman, D. Wilkie, N. Brokaw, and M. Martinez. 1997. Household determinants of deforestation by Amerindians in Honduras. World Development 25:977-987.

Godoy, R., D. Wilkie, H. Overman, A. Cubas, G. Cubas, J. Demmer, K. McSweeney, and N. Brokaw. 2000.
Valuation of consumption and sale of forest goods from a Central American rain forest. Nature 406:62-63.

Godoy, R. A., and K. S. Bawa. 1993. The economic value of sustainable harvest of plants and animals from the tropical forest: assumptions, hypotheses, and methods. Economic Botany 47:215-219.

Gordon, W. F., S. B. Vinson, L. E. Newstrom, J. F. Barthell, W. A. Haber, and J. K. Frankie. 1990. Plant phenology, pollination ecology, pollinator behaviour and conservation of pollinators in Neotropical dry forest. Pages 37-48 in K. S. Bawa and M. Hadley, editors. Reproductive ecology of tropical forest plants. MAB (Man and Biosphere) series 7, UNESCO, Paris, France.

Gram, S. 2001. Economic valuation of special forest products: an assessment of methodological shortcomings. Ecological Economics 36:109-117.

Grimes, A., S. Loomis, P. Jahnige, M. Burnham, K. Onthank, R. Alarcon, W. Palacios Cuenca, C. Ceron Martínez, D. Neill, M. Balick, B. Bennett, and R. Mendelsohn. 1994. Valuing rain forest. Ambio 23:405-410.

Hamilton, A., and R. Bensted-Smith, editors. 1989. Forest conservation in the East Usambara Mountains Tanzania. World Conservation Union. Gland, Switzerland.

Henning, D. H. 1998. Buddhism and Deep Ecology: protection of spiritual and cultural values for natural tropical forests in Asia. Pages 108-112 in A. E. Watson, editor. Personal, societal, and ecological values of wilderness: Proceeedings of the Sixth World Wilderness Congress. Volume 1. U.S. Forest Service, Rocky Mountain Research Station, Proceedings RMRS-P-4.

Hoben, A. 1995. Paradigms and politics: the cultural construction of environmental policy in Ethiopia. World Development 23:1007-1021.

Hyde, W. F., G. S. Amacher, and W. B. Magrath. 1996. Deforestation and forest land use: theory, evidence and policy implications. The World Bank Research Observer 11:2.

Jenkins, T. N. 1996. Democratising the global economy by ecologicalising economics: the example of global warming. Ecological Economics 16:227-238.

Jenkins, T. N. 1998. Economics and the environment: a case of ethical neglect. Ecological Economics 26:151-163.

Jodha, N. S. 2000. Common property resources and the dynamics of rural poverty: field evidence from the dry regions of India. Pages 203-221 in W. F. Hyde and G. S. Amacher, editors. Economics of forestry and rural development: an empirical introduction from Asia. University of Michigan Press, Ann Arbor, Michigan, USA.

Kaimowitz, D., and A. Angelsen. 1998. Economic models of tropical deforestation: a review. Center for International 
Forestry Research, Bogor, Indonesia.

Keeley, J., and I. Scoones. 1999. Understanding environmental policy processes: a review. Institute of Development Studies (IDS) Working Paper 89. Sussex University, UK. [Online, URL: http://www.ids.ac.uk/ids/env/pubs 1999.html]

Kuhn, T. S. 1962. The structure of scientific revolutions. University of Chicago Press, Chicago, Illinois, USA.

Lampietti, J., and J. A. Dixon. 1995. To see the forest for the trees: a guide to non-timber forest benefits. Environment Department Papers Number 013. The World Bank, Washington, D.C., USA.

Linddal, M. 1993. The quasi-option value from irreversible loss of biodiversity. Scandinavian Forest Economics 34:5873.

Lindsay, S. W., L. Parson, and C. J. Thomas. 1998. Mapping the ranges and relative abundance of the two principal African malaria vectors, Anopheles gambiae sensu stricto and An. arabiensis, using climate data. Proceedings of the Royal Society of London, Series B 265:847.

Loomis, J. B. 2000. How do people love their forests? Let me count the ways. IUFRO (International Union of Forest Research Organizations) World Congress XXI:654-661. Kuala Lumpur, Malaysia, 7-12 August 2000. Volume 1: Sub-Plenary Sessions. IUFRO Secretariat, Vienna, Austria.

Melnyk, M., and N. Bell. 1996. The direct use values of tropical moist forest foods: the Huottuja (Piaroa) Amerindians of Venezuela. Ambio 25:468-472.

Nemarundwe, N., and M. Richards. 2002. Participatory methods for exploring livelihood values derived from forests: potential and limitations. Pages 168-197 In B. M. Campbell and M. K. Luckert, editors. Uncovering the hidden harvest. Valuation methods for woodland and forest resources. People and plants conservation manual series. Earthscan Publications, London, UK.

Ostrom, E. 1999. Self-governance and forest resources. CIFOR Occasional Paper Number 20, Center for International Forestry Research, Bogor, Indonesia.

Owen, L. A., and T. Unwin, editors. 1997. Pages 35-39, Environmental management: readings and case studies. Blackwell, Oxford, UK.

Padoch, C., and W. de Jong. 1989. Production and profit in agroforestry: an example from the Peruvian Amazon. Pages 102-113 in J. G. Browder, editor. Fragile lands of Latin America: strategies for sustainable development. Westview Press, Boulder Colorado, USA.

Panayotou, T., and P. S. Ashton. 1992. Not by timber alone: economics and ecology for sustaining tropical forests. Island Press, Washington D.C., USA.
Pendleton, L. H. 1992. Trouble in paradise: practical obstacles to nontimber forestry in Latin America. Pages 252-262 in M. Plotkin and L. Famolare, editors. Sustainable harvest and marketing of rain forest products. Island Press, Washington D.C., USA.

Peters, C. M., A. H. Gentry, and R. O. Mendelsohn. 1989. Valuation of an Amazonian rainforest. Nature 339:655-656.

Pinedo-Vásquez, M., D. Zarin, and P. Jipp. 1992. Economic returns from forest conversion in the Peruvian Amazon. Ecological Economics 6:163-177.

Roubik, D. W. 2002. Tropical agriculture: the value of bees to the coffee harvest. Nature 417:708.

Ruitenbeek, H. J. 1990. Economic analysis of tropical forest conservation initiatives: examples from West Africa. World Wide Fund for Nature, Godalming, Surrey, UK.

Salafsky, N. 1995. Ecological factors affecting durian production in the forest gardens of West Kalimantan, Indonesia. A GIS-based cross-sectional analysis of a locally-developed agroforestry system. Agroforestry Systems 32:63.

Scott, J. C. 1998. Seeing like a state. The Yale ISPS series. Yale University Press, New Haven, Connecticut, USA.

Schroeder, H. W. 1989. Psychological and cultural effects of forests on people. Pages 10-14 in Healthy forests, healthy world. Proceedings of the 1988 Society of American Foresters National Convention. Society of American Foresters, Bethesda, Mayland,USA.

Sheil, D., R. K. Puri, I. Basuki, M. van Heist, Syaefuddin, Rukmiyati, M. A. Sardjono, I. Samsoedin, K. Sidiyasa, Chrisandini, E. Permana, E. M. Angi, F. Gatzweiler, and A. Wijaya. 2002. Exploring biological diversity, environment and local people's perspectives in forest landscapes. CIFOR, (Ministry of Forestry, Republic of Indonesia) MOF, and ITTO, Bogor, Indonesia. [Online, URL: http://www.cifor.cgiar.org/publications/index.htm.]

Sheil, D., editor. 2002, in press. Biodiversity research in Malinau. Chapter 5 in CIFOR and ITTO 2002. Technical Report, Phase I (1997-2001). Forest, science and sustainability: the Bulungan Model Forest. ITTO Project PD 12/97 Rev.1 (F). CIFOR, MOF, and ITTO, Bogor, Indonesia. [Online, URL: http://www.cifor.cgiar.org/publications/index.htm.]

Sheil, D., N. Liswanti, M. van Heist, I. Basuki, Syaefuddin, I. Samsoedin, Rukmiyati, M. Agung. In press. Local priorities and biodiversity in tropical forest landscapes: asking people what matters. Tropical Forest Update. [Online, URL: http://www.itto.or.jp.]

Smith, N., J. Dubois, D. Current, E. Lutz, and C. Clement. 1998. Agroforestry experiences in the Brazilian 
Amazon: constraints and opportunities. The World Bank (Brazil Rain Forest Unit) and the Brazilian Ministry of Environment, Secretariat for the Coordination of Amazon Affairs, Brasília, Brazil.

Soderbaum, P. 1999. Values, ideology and politics in ecological economics. Ecological Economics 28:161-170.

Southgate, D. 1990. The causes of land degradation along "spontaneously" expanding agricultural frontiers in the Third World. Land Economics 66(1):93-101.

Spilsbury, M. J., and D. Kaimowitz. 2000. The influence of research and publications on conventional wisdom and policies affecting forests. Unasylva 51(4):3-10.

Thompson, S. K. 1992. Sampling. Wiley-Interscience Publication, New York, New York, USA.

Watson, R. T., M. C. Zinyoweraand, and R. H. Moss, editors. 1996. Impacts, adaptations and mitigation of climate change: scientific technical analysis. Contribution of Working Group II to the Second Assessment Report of the Intergovernmental Panel on Climate Change [IPCC]. Cambridge University Press, Cambridge, UK.

Westoby, J. 1989. Introduction to world forestry. Blackwell, Oxford, UK.

Wollenberg, E. 1998. Estimating the incomes of people who depend on forests. Pages 157-187 in E. Wollenberg and A. Ingles, editors. Incomes from the forest: methods for the development and conservation of forest products for local communities. Center for International Forestry Research, Bogor, Indonesia.

Wunder, S. 1996. Deforestation and the uses of wood in the Ecuadorian Andes. Mountain Research and Development 16:367-381. 